\title{
Research of Female Consumer Behavior in Cosmetics Market Case Study of Female Consumers in Hsinchu Area Taiwan
}

\author{
Chang-Tzu Chiang, Wan-Chen Yu
}

Department of Business Administration, Yuanpei University, Hsinchu, Taiwan, China.

E-mail: wanchen1110@hotmail.com

Received July $17^{\text {th }}, 2010$; revised August $16^{\text {th }}, 2010$; accepted September $27^{\text {th }}, 2010$.

\begin{abstract}
The rapidly changing social situation in the latter part of the 20th century, such as revolutionary movement for women's equal rights, significantly affects the women consumer behaviors as well as improves their social status. The awakening of female consumer's consciousness during the recent years leads to alteration of consumer behavior, and influences the women's usual conception for pursuing fashion and cosmetics application, in fact, the makeup practice has already been regarded as a social politeness and necessary requirement for interpersonal activities. By employing the Means-End Chain theory, this study intends to explore the attribute, result, and value attached importance by female consumer towards cosmetic products, in order to realize consumer's cosmetics application process. The female consumers in Hsinchu are taken as research targets for this study to conduct variable analysis of their lifestyle and demographic statistics. Totally 550 questionnaires were released and 390 copies are effective among the retrieved ones. Methods as factor analysis and ANOVA are applied for examining various study hypotheses. Moreover, the implementation of Means-End Chain theory allows cosmetics industry to better understand the signification of product attribute valued by consumers so as to anticipate the details of consumer result and value recognition experienced by consumers.
\end{abstract}

Keywords: Lifestyle Variable, Demographic Statistics Variable, Product Attribute, Mean-End Chain, Consumer Behavior

\section{Introduction}

The rapidly changing social situation in the latter part of the 20th century, such as revolutionary movement for women's equal rights, significantly affects the women consumer behaviors as well as improves their social status. The female consumers hold a different view about applying cosmetics ever since, in other words, they consider wearing cosmetics not only for enhancing selfconfidence but also is a form to express social politeness. According to the data provided by Industrial Technology Research Institute, as much as US\$ 0.1548 billion is worth the global cosmetics market in 2001, and the sum is expected to soar to US $\$ 0.1817$ billion in 2008 (i.e., NT\$ 6.3595 billion) [1]. As indicated in the World Market for Cosmetics and Toiletries, a comprehensive analysis of the cosmetics and toiletries market offered by Euro monitor International in June 2007, covering 52 countries of global $95 \%$ GDP, and the global market size is expected to reach US\$ 0.23 billion in 2009, while Asia would become the largest cosmetics market in the whole world from 2011 to 2013. In the meantime, the lifestyle and taste for fashion of women consumers will turn to far more diversified along with the constant market expansion. Lifestyle is definitely an important factor for studying consumer behavior; according to the lifestyle concept presented by Lazer [2], the lifestyle concept may facilitate revealing the potential consumer behavior, in addition, the Means-End Chain (MEC) offered by Gutman [3], the theory the most used for analyzing the association between product and customer in the marketing documentation. The major methods for measuring lifestyle frequently used in the market at present include Values and Lifestyle Survey (VALS) and AIO scale (Activity, Interests, Opinion Inventory). The Means-End Chain (MEC) theory presented by Gutman [3], is extensively applied for exploring consumer behavior, and explicitly defining the structure among three levels, namely, product attributes, purchase result, as well as outcome produced by individual value. The theory is based on the 
final value status desired by value concept of consumer behavior, not only for determining which benefit perception among benefit variables of a certain product could better satisfy the value demand of consumer, but also for assisting manufacturer to recognize the benefit characteristics provided by various products fabricated, in order to reach the sales volume target and realize which type of product or service can best satisfy consumer demands. Since the majority of cosmetics customers are female, who are therefore the target interviewees of questionnaire designed by this study, besides, the association between different lifestyle and product attribute, result and final value would be further investigated.

\section{Empirical Study}

By taking several factors into account, such as limited manpower, budget and time, this study adopts Random sampling strategy, with the support of classmates and relatives, the survey was conducted at some majors cosmetics distributions channels in Hsinchu city, such as special counter in department store and drug \& cosmetics chain store. The questionnaires were filled out by female consumers qualified for random sampling. Totally 550 questionnaires were released and 525 were retrieved, after eliminating 35 copies with incomplete responses and 100 copies replied by interviewees by checking both working and residential locations outside of Hsinchu city, the retrieved effective questionnaires are 390 copies $(70.9 \%)$. The main research variables defined by this study contain five dimensions: lifestyle of consumer, product attribute, result of using, personal value, and demographic statistics. The questionnaire survey is employed by this study as research tool, the structured questionnaire technique is used for survey design, and five-point Likert scale is used for interviewees to check the appropriate answer. The hypotheses of this study are based on the comparison of consumers of different lifestyle, supposing the cosmetics consumer behavior would affected by lifestyle and demographic statistics, even further influence the overall structure. The major hypotheses presented by this study are given as follows:

Hypothesis $1\left(\mathrm{H}_{1}\right)$ : There is significant difference between consumers of different lifestyle in each attribute.

$\mathrm{H}_{1.1}$ : There is significant difference between consumers of different lifestyle in attribute (tangible).

$\mathrm{H}_{1.2}$ : There is significant difference between consumers of different lifestyle in attribute (intangible).

Hypothesis $2\left(\mathrm{H}_{2}\right)$ : There is significant difference between consumers of different lifestyle in each result.

$\mathrm{H}_{2.1}$ : There is significant difference between consumers of different lifestyle in result (functionality).

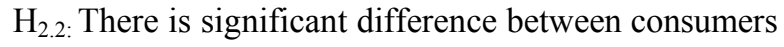
of different lifestyle in result (psycho-social nature).
Hypothesis $3\left(\mathrm{H}_{3}\right)$ : There is significant difference between consumers of different lifestyle in each value.

$\mathrm{H}_{3.1}$ : There is significant difference between consumers of different lifestyle in value (self-respect).

$\mathrm{H}_{3.2}$ : There is significant difference between consumers of different lifestyle in value (self-satisfaction).

$\mathrm{H}_{3.3}$ : There is significant difference between consumers of different lifestyle in value (excitement).

$\mathrm{H}_{3.4}$ : There is significant difference between consumers of different lifestyle in value (sense of accomplishment).

$\mathrm{H}_{3.5}$ : There is significant difference between consumers of different lifestyle in value (fun and enjoyment).

$\mathrm{H}_{3.6}$ : There is significant difference between consumers of different lifestyle in value (warm relations with others).

$\mathrm{H}_{3.7}$ : There is significant difference between consumers of different lifestyle in value (sense of belonging).

$\mathrm{H}_{3.8}$ : There is significant difference between consumers of different lifestyle in value (security).

$\mathrm{H}_{3.9}$ : There is significant difference between consumers of different lifestyle in value (reverence).

Hypothesis $4\left(\mathrm{H}_{4}\right)$ : There is significant difference between consumers with different demographic variables in valued product attrite - value - result.

$\mathrm{H}_{4.1}$ : There is significant difference between women of different age in valued product attribute.

$\mathrm{H}_{4.2}$ : There is significant difference between women of different marital status in valued product attribute.

$\mathrm{H}_{4.3}$ : There is significant difference between women with different education degree in valued product attribute.

$\mathrm{H}_{4.4}$ : There is significant difference between women with different occupation in valued product attribute.

$\mathrm{H}_{4.5}$ : There is significant difference between women with different monthly income in valued product attribute.

$\mathrm{H}_{4.6}$ : There is significant difference between women with different monthly budget on non-necessities expenses in valued product attribute.

$\mathrm{H}_{4.7}$ : There is significant difference between women with different monthly budget for purchasing cosmetics in valued product attribute.

$\mathrm{H}_{4.8}$ : There is significant difference between women different in age started to use skin care product in valued product attribute.

$\mathrm{H}_{4.9}$ : There is significant difference between women different in age started to apply color cosmetics in valued product attribute.

$\mathrm{H}_{4.10}$ : There is significant difference between women with different shopping information sources in valued product attribute.

A pre-test was carried out before officially releasing 
the questionnaire designed by this study. For applying the pre-test on samples, 30 interviewees were asked to fill out the pre-test questionnaire, and to write down any inappropriate contents required to be corrected, such as phrases not colloquial enough or the inexplicit meanings, hence all the interviewees fully understanding the question items of official questionnaire will be allowed to check the appropriate answer with certainty. Based on the pre-test questionnaires retrieved, this paper performed SPSS statistics software for reliability analysis, and verified the internal consistency with Cronbach's $\alpha$ value. The overall reliability achieved 0.67 (Table 1), proving this questionnaire has consistency and with reliability within acceptable range, besides, the reliability after removing each question item has not increased significantly, this study thus did not eliminate any question item, the questionnaire was therefore ready to be released. The general reliability measurement is most frequently used for examining the internal consistency of questionnaire, the consistency and stability value of measurement result are Cronbach's $\alpha$ coefficient, the higher Cronbach's $\alpha$ coefficient is, the higher consistency of variables to be measured exists between each question item will be, indicating the high reliability of question items in questionnaire. The Cronbach's $\alpha$ coefficient presented by Guilford (1965) is supposed to be higher than 0.70 , the coefficient between $0.70-0.35$ is acceptable, but the value under 0.35 should be dropped. Moreover, Churchill (1995) suggests eliminating question item with correlation coefficient of total single item under 0.50 for improving Cronbach's $\alpha$ coefficient and ensuring the reliability quality of question item.

This study uses SPSS statistical software as analytical research tool, to statistically analyze the coded information in the database for producing statistical analysis report; the analysis items of this paper are descriptive statistics, reliability analysis, factor analysis, and variance analysis, the details are listed as follows:

1) Descriptive Statistics

Analyze the mean, standard deviation, and percentage of variables through descriptive statistics method, for directing an initial generalized analysis and identifying the sample structure of this study.

2) Reliability Analysis

The most frequently used domestically - Cronbach's $\alpha$ coefficient is employed by this study for examining the

Table 1. Overall reliability of pre-test questionnaire.

\begin{tabular}{ll}
\hline Cronbach's $\alpha$ value & Number of Item \\
\hline 0.673 & 120 \\
\hline
\end{tabular}

internal consistency. Cronbach's $\alpha$ coefficient over 0.7 means high reliability, 0.7-0.35 is acceptable, and under 0.35 is classified as low reliability. Nevertheless, Cronbach's $\alpha$ coefficient higher than 0.65 is adopted by this study as standard for reliability analysis of questionnaire scale.

3) Factor Analysis

The factor analysis carried out by this study was focusing on lifestyle, attribute, result, and personal value. The factors obtained through major component analysis, for extracting factor with eigenvalue over 1 as standard, then select appropriate numbers in accordance with the requirement of this study, followed by orthogonal rotation with the maximum variation, in order to make structure of each factor be more explicit.

4) Variance Analysis

The main purpose of this study is to identify if there is significant difference between different lifestyles in attribute and structure, and analyze if significant different shown on consumers with different lifestyle, different attribute, and different result in demographic statistics.

\section{Empirical Result}

This paper analyzes the effective samples; the NT\$10003000 takes the largest proportion as monthly expenses on non-necessities - $40 \%$, the monthly budget for purchasing cosmetics is mostly under 3000 , among others, $1000-3000$ is at the top place with $53.6 \%$, followed by less than $1000(41 \%)$, while $5000-7000$ takes only $0.5 \%$. As to age started to use skin care products, the majority of interviewees, $57.5 \%$, began under 18 years old, next one is $19-25$ with $38.2 \%$; the most respondents started to apply color cosmetics are at the age between 19-25 (58.7\%) followed by $36.9 \%$, women under 18 , indicating that the group of applying skin care products and color cosmetics are relatively younger. By categorizing the age of female consumers, the cosmetics users are relatively of lower age, most of them are students, with quite low income, but manifest higher willingness of using toiletries and color cosmetics. Numerous shopping information sources are accessible to consumers, according to the data collected, female consumers acquire information through various channels, television is the main source by $26.7 \%$, followed by DM advertisement by $25.9 \%$, and the third one is newspaper and magazine.

The Cronbach's $\alpha$ reliability coefficient value and variances extracted are used for measuring the internal consistency of questionnaire. The Cronbach's $\alpha$ reliability coefficient value obtained from overall analysis of lifestyle, product attribute, benefit (result) and value reached as high as 0.706 (Table 2), proving the reliability of this questionnaire. 
Table 2. Overall reliability of official questionnaire.

\begin{tabular}{ll}
\hline Cronbach's $\alpha$ value & Item Numbers \\
\hline 0.706 & 120 \\
\hline
\end{tabular}

This study selects factor loading with absolute value over 0.5 , eigenvalue greater than 1 , and cumulative explained variance over $50 \%$, as criteria of factor extraction, and a name will be given accordingly. After shaft analysis, six lifestyle factor dimensions were extracted from the result, the shaft cumulative explained variance reached $52.928 \%$, and the names given are: "active consumers, traditional consumer, enthusiastic consumer, impulsive consumers, practical consumer, and cautious consumer". As to product attributes dimension, 2 product dimensions were obtained from factor extraction result, and the names designated are tangible and intangible based on variable explained by each factor. As to the benefit (result) dimension, 2 result dimensions were obtained through factor analysis, according to variable value explained by each factor, the dimension names extracted from benefit (result) are functionality and psycho-social nature. In terms of value dimension, 9 values were extracted through factor analysis, in accordance with variable value explained by each factor, the benefit (result) dimension extracted were obtained, and the names assigned are self respect, self-satisfaction, excitement, sense of accomplishment, fun and enjoyment, warm relations with others, sense of belonging, security, and reverence.

Between consumers of different lifestyle in tangible value and intangible value of product, the results of ANOVA test are listed in Table 3; all the significant values are less than 0.005 , indicating there is significant difference shown by consumers with different lifestyle while purchasing cosmetics due to tangible value and intangible value of product. This study accepts consequently the hypothesis 1 , there is significant difference between consumers of different lifestyle in each attributes.

Between consumers of different lifestyle in functionality result and psycho-social nature, the ANOVA test shows in Table 4, the significant value is always less than 0.005 , proving there is significant difference while

Table 3. ANOVA of lifestyle in product attributes.

\begin{tabular}{lllllll}
\hline \multirow{2}{*}{ product dimensions } & \multicolumn{2}{c}{ tangible } & & \multicolumn{2}{c}{ intangible } \\
\cline { 3 - 4 } \cline { 6 - 7 } lifestyle factor & \multicolumn{1}{c}{$\mathrm{F}$} & $\mathrm{P}$ & & $\mathrm{F}$ & $\mathrm{P}$ \\
\hline active consumers & 31.835 & 0.0001 & & 20.023 & 0.0001 \\
traditional consumer & 68.714 & 0.0001 & & 11.939 & 0.0001 \\
enthusiastic consumer & 11.562 & 0.0001 & & 35.068 & 0.0001 \\
impulsive consumers & 26.984 & 0.0001 & & 21.511 & 0.0001 \\
practical consumer & 23.242 & 0.0001 & & 22.177 & 0.0001 \\
cautious consume & 5.479 & 0.0001 & & 18.494 & 0.0001 \\
\hline
\end{tabular}

consumers of different lifestyle in purchasing cosmetics caused by product functionality and psycho-social nature. This study thus accepts the hypothesis 2 , there is significant difference between consumers of different lifestyle in each result.

The ANOVA test of between consumers of different lifestyle in the value provided by product, including self-respect, self-satisfaction, excitement, sense of accomplishment, fun and enjoyment, warm relations with others, sense of belonging, security, and reverence, as shown in Table 5, most significant value is less than 0.005 , signifying consumers of various lifestyle are different in purchasing cosmetic owing to different value of product; while significant value is 0.160 for active consumers towards security value, showing there is no significant difference between active consumers in if the product provides security value. As a whole, this study accepts the hypothesis 3, there is significant difference between consumers of different lifestyle in each value.

The ANOVA is made on demographic statistics to product attributes, product result, and product value. As indicated in Table 6, the product attributes, product result, and product value will not be varied due to the difference in age, marital status, education degree, occupation, monthly income, monthly spending on non-necessities, monthly budget for cosmetics, age started to use skin care products, age started to apply color cosmetics, and shopping information. This study rejects therefore the hypothesis 4 , as there is no significant difference in product attributes - value - result valued by consumers of different demographic statistics variables.

\section{Conclusions and Recommendation}

This study was designed with questionnaires for surveying cosmetics consumers in Hsinchu area market as research targets, through factor analyzing, six types of female consumers are classified, specifically, "active consumer", "traditional consumer", "enthusiastic consumer", "impulsive consumer", "practical consumer", and "cautious consumer", moreover, variable analysis was conducted for investigating the difference of each demo-graphic variables in product attributes-result-value. According to the

Table 4. ANOVA of lifestyle to product result.

\begin{tabular}{llllllc}
\hline \multirow{2}{*}{ product result } & \multicolumn{2}{c}{ functionality } & & \multicolumn{2}{c}{ psycho-social nature } \\
\cline { 6 - 6 } \cline { 5 - 6 } lifestyle factor & \multicolumn{1}{c}{$\mathrm{F}$} & $\mathrm{P}$ & & $\mathrm{F}$ & $\mathrm{P}$ \\
\hline active consumers & 14.795 & 0.0001 & & 10.454 & 0.0001 \\
traditional consumer & 47.259 & 0.0001 & & 66.638 & 0.0001 \\
enthusiastic consumer & 4.244 & 0.0001 & & 13.208 & 0.0001 \\
impulsive consumers & 91.389 & 0.0001 & & 28.287 & 0.0001 \\
practical consumer & 50.755 & 0.0001 & & 37.581 & 0.0001 \\
cautious consume & 27.622 & 0.0001 & & 7.933 & 0.0001 \\
\hline
\end{tabular}


Table 5. ANOVA of lifestyle to product value.

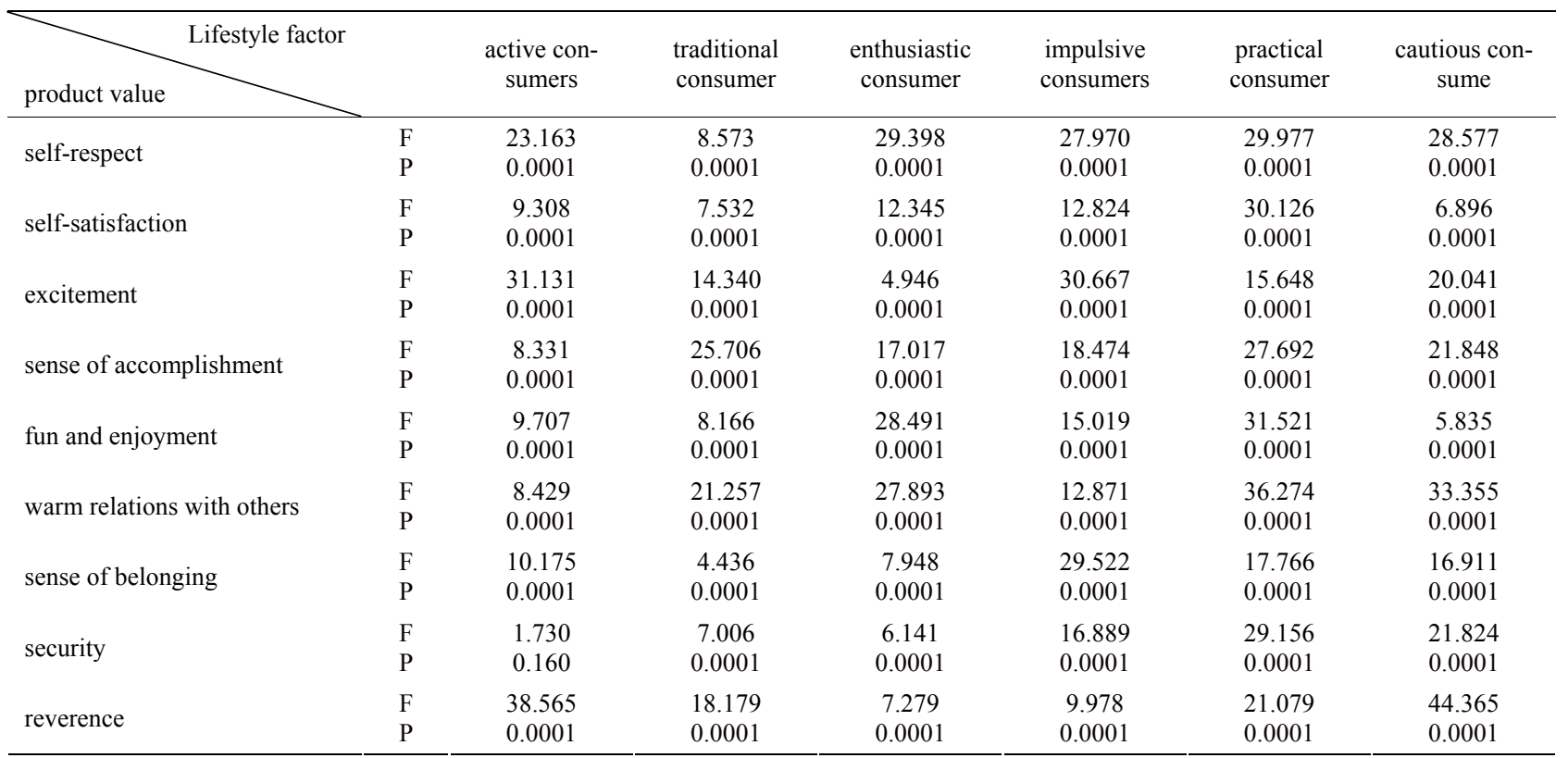

Table 6. Analysis of demographic variance.

\begin{tabular}{|c|c|c|c|c|}
\hline Demographic Variance & & Attributes & Consequences & Value \\
\hline \multirow{2}{*}{ age } & $\mathrm{F}$ & 2.397 & 0.786 & 1.582 \\
\hline & $\mathrm{p}$ & 0.050 & 0.535 & 0.178 \\
\hline \multirow{2}{*}{ marital status } & $\mathrm{T}$ & 0.691 & -0.116 & 0.293 \\
\hline & $\mathrm{p}$ & 0.490 & 0.908 & 0.770 \\
\hline \multirow{2}{*}{ education degree } & $\mathrm{F}$ & 0.112 & 0.775 & 0.497 \\
\hline & $\mathrm{p}$ & 0.953 & 0.508 & 0.684 \\
\hline \multirow{2}{*}{ occupation } & $\mathrm{F}$ & 1.223 & 0.469 & 1.290 \\
\hline & $\mathrm{p}$ & 0.289 & 0.857 & 0.254 \\
\hline \multirow{2}{*}{ monthly income } & $\mathrm{F}$ & 2.430 & 0.320 & 0.577 \\
\hline & $\mathrm{p}$ & 0.035 & 0.901 & 0.718 \\
\hline \multirow{2}{*}{ monthly spending on non-necessities } & $\mathrm{F}$ & 0.468 & 1.125 & 0.192 \\
\hline & $\mathrm{p}$ & 0.760 & 0.344 & 0.942 \\
\hline \multirow{2}{*}{ monthly budget for cosmetics } & $\mathrm{F}$ & 1.557 & 0.733 & 0.418 \\
\hline & $\mathrm{p}$ & 0.043 & 0.533 & 0.740 \\
\hline \multirow{2}{*}{ age started to use skin care products } & $\mathrm{F}$ & 0.580 & 0.623 & 1.048 \\
\hline & $\mathrm{p}$ & 0.628 & 0.601 & 0.371 \\
\hline \multirow{2}{*}{ age started to apply color cosmetics } & $\mathrm{F}$ & 0.887 & 0.044 & 4.357 \\
\hline & $\mathrm{p}$ & 0.448 & 0.988 & 0.006 \\
\hline \multirow{2}{*}{ shopping information } & $\mathrm{F}$ & 3.595 & 1.075 & 2.364 \\
\hline & $\mathrm{p}$ & .007 & 0.369 & 0.053 \\
\hline
\end{tabular}

finding of this study, significant difference is shown between consumers of different lifestyle towards attribute, result, and value. While the product attribute - result value attached importance by consumers of different demographic variance will not vary on account of age, education degree, occupation, marital status, and shopping information sources. Finally, this study suggests that future researchers may try to expand the population 
and perform sampling and comparison between different metropolitan areas; the cosmetics industry is supposed to better understand the expectation put forward by cosmetics consumers as well as the significance of the value, so as to use it as reference in product manufacturing and marketing development. As to the analytic data demographic variables, lifestyle, and value, could assist cosmetics industry in designing the future marketing strategies.

\section{REFERENCES}

[1] K. S. Zhao and X. M. Zhang, "Cosmetics Chemistry," Wunan Publisher, Taipei, 2006.

[2] W. Lazer, "Life style Concepts and Marketing toward Scientific Marketing, Stephen Cresysered," AMA, Chicago, 1963.

[3] J. Gutman, "A Means-End Chain Model Based on consumer Categorization Processes," Journal of Marketing, Vol. 46, No. 2, 1982, pp. 60-72. 